\title{
Green Nanoparticles Investigation to Remove Water Pollutants by Fenton Reaction Using Celery Leaves Extract
}

\author{
Saba N. Fayyadh ${ }^{1,2 *}$, Nurfaizah A. Tahrim ${ }^{1}$ \\ ${ }^{1}$ Department of Chemical Sciences, Faculty of Science and Technology, Universiti Kebangsaan Malaysia, 43600 Bangi, \\ Selangor, Malaysia \\ ${ }^{2}$ College of Education for Pure Science (Ibn al-Haitham), University of Baghdad, Baghdad 10013, Iraq
}

Corresponding Author Email: p95770@ sisw.ukm.edu.my

https://doi.org/10.18280/ijdne.150304

Received: 12 January 2020

Accepted: 6 April 2020

\section{Keywords:}

environmental pollutants, water treatment, Fenton process, $C$ - $n Z V F e$, green chemistry, dyes

\begin{abstract}
Wastewater containing dyes is a major source of environmental pollution. The purpose of this study is to evaluate the use of celery leaves extract employed to prepare zerovalent Iron nanoparticles (C-nZVFe) as a catalyst in Fenton reaction. The getting nanoparticles are then applied to decolorization aqueous solutions containing orange (OG) dyes. The C-nZVFe catalyst has been characterized by Fourier transformed infrared (FTIR) spectroscopy, X-ray diffraction (XRD), Field emission scanning electron microscopy (FESEM) techniques for the investigation of structural and surface morphology properties. The size and surface area of synthesized C-nZVFe are observed around $40-55 \mathrm{~nm}$. Using ultraviolet-visible (UV - vis) spectroscopy, the amount of dye in the aqueous sol is observed. Orange $\mathrm{G}$ removal percentage $\left(100 \mathrm{mg} \mathrm{L}^{-1}\right)$ reached $86 \%$ [35 $\mathrm{mg} \mathrm{L}^{-1}, 60 \mathrm{~min}$, and $\mathrm{pH}$ 4]. C-nZVFe nanoparticles demonstrated more efficient percentage capacity as a Fenton catalyst removal and are more economical, efficient, and recyclable than other conventional Fenton oxidation catalysts.
\end{abstract}

\section{INTRODUCTION}

Water pollution occurs when pollutants are leaked into waterways either directly or indirectly without regard to pretreatment for the removal of hazardous compounds. The textile sector is one of the world's most significant sources of water pollution [1]. The World Bank estimates the industrial water released at about $20 \%$ is caused by tinting and fabric treatment. Globally, the agriculture sector is rising clean water polluter. The textile sector is ranked second on the list [2]. Statistics showed that $90 \%$ of all colors were used in the coloring of fabrics and the rest in the food and chemical industries. Textile termination effluents, for example, account for $22 \%$ of the total volume of industrial wastewater generated in Malaysia. Water is a good way to carry organic compounds in their molecules, with polar groups. The presence of sulphonic groups in the dye makes these groups polar and water-soluble. The azo dye which contains polar groups in its molecular structures is therefore easily transferred from one water matrix to another [3]. Azo dyes, one of the largest classes of synthetic dyes, have one or more azo bonds $(-\mathrm{N}=$ $\mathrm{N}-$ ) and are commonly used in many applications, due to their solubility, low cost, stability and color variety [4]. Orange G is one of the rising colorants. (OG) is an acid azo dye, used as a color indicator, $\mathrm{pH}$ marker, stain keratin and also widely used in food industry, textile, paper printing, pharmaceutical; leather and cosmetics [5]. The presence of these component in the environment is considered unacceptable not only because of color but because of their high toxicity and poor degradability. In the past few decades, with the increase in water demand, strict regulations have been developed to reduce pollution from its consumption.
There are several ways to eliminate these dyes from wastewater, including biological treatments, ultrafiltration, oxidation, coagulation, and physical treatments such as ozone, nanofiltration, adsorption, and chemicals such as the Fenton process and other advanced oxidation processes (AOP) [6]. AOP is an effective, promising, efficient and environmentally friendly method developed for generally extracting POPs from water and wastewater. This technology features its simple equipment, is easy to operate and automate, and no more chemicals are needed [7].

Recent studies have concentrated on the water quality and developing less costly treatment systems to tackle the biological toxicity of organic contaminants in surface water and wastewater [8]. The traditional and most widely used chemical advance oxidation process is the Fenton procedure, in which a blend of soluble Fe (II) salt and $\mathrm{H}_{2} \mathrm{O}_{2}$, renowned as the Fenton reagent, is applied to degrade and eliminate persistent organic pollutants (POPs) (Fenton, 1894). Fenton processes include the production of highly reactive, lowselectivity oxygen (ROS), such as hydroxyl radicals (HO), which have been prove to form due to a series of reactions consisting of iron and iron salts and catalytic hydrogen peroxide breaking in addition to other factors such as reaction time, $\mathrm{pH}$ and temperature, which are essential parameters for ease of operation and maintenance giving tract of complete mineralization to $\mathrm{CO}_{2}, \mathrm{H}_{2} \mathrm{O}$ and inorganic ions or acids [9]. The Fenton reaction is characterized by its low cost and high efficiency in removing and degrading non-degradable organic contaminants in water and is considered one of the fastest advanced mechanisms of oxidation [10]. The general Fenton reaction (Fenton homogeneous reaction) requires equivalent quantities of $\mathrm{H}_{2} \mathrm{O}_{2}$ and $\mathrm{Fe}^{+2}$, at optimum $\mathrm{pH}$ 2.5-3.0. According 
to Munoz et al. [11] dissolved iron salt cannot be recycled in this homogeneous system, so the additional treatment process can produce a significant volume of iron oxide sludge. Separating iron and sludge salts from treated water needs more effort and expense, and because of a final disposal problem, the process is often limited. To solve the drawbacks of the traditional Fenton reaction, (heterogeneous Fenton reaction) was developed by Fe solid supported catalysts such as pyrite and hematite [12].

Many researchers have been interested in developing new methods for creating heterogeneous catalysts that support Fenton interaction using nanocatalyst technology [13]. Iron nanoparticles have recently gained much attention in environmental treatment methods. One of the most promising applications in the removal of organic and inorganic contentious in water solutions $[14,15]$. In the Fenton process nanoparticles containing zero irons ions (n-ZVFe) can also be used as a catalyst to remove organic from water solutions [16, [17]. The compact nano-size provides ample surface area and investable pores in removal pollutants. Many studies indicate that nanocatalyst they are low cost, easy to operate, and can show good results by integrating the ability of the Fenton reagent with the advantages of Fe nanoparticles (FeNPs).

Green chemistry for nanoparticles production is among the most significant and environmentally friendly alternatives available at a low cost $[18,19]$. Hitherto, green chemistryprepared Fe nanoparticles have proven effective in removing various pollutants. The purpose of this work is to estimate the efficiency of the catalyst used in the Fenton reaction and its ability to remove the staining of the dye. The iron nanoparticles created from green plants were prepared as a catalyst in the Fenton reaction, using celery leaves. To establish the best experimental environment for color removal from orange $\mathrm{G}$, the dose of nanocatalyst, initial dye concentration, and $\mathrm{pH}$ were improved. The $\mathrm{pH}$ and UV spectrum variations were tracked both before and after removal of the dye [20].

\section{CHEMICALS AND REAGENTS}

Both chemicals and analytical reagents used are of the highest purity grade; namely, Ferrous Sulphate dehydrate $\left(\mathrm{FeSO}_{4} \cdot 7 \mathrm{H}_{2} \mathrm{O}\right), \mathrm{H}_{2} \mathrm{O}_{2}(30 \%)$, Merck Co. Ltd.) Ltd. Using sulfuric acid $\left(\mathrm{H}_{2} \mathrm{SO}_{4}, 98 \%\right)$, and sodium hydroxide $(\mathrm{NaOH})$, the $\mathrm{pH}$ is adjusted. Malaysia's celery plant using to prepare a catalyst for the heterogeneous Fenton processes. Orange $G$ $\left(\mathrm{C}_{16} \mathrm{H}_{10} \mathrm{~N}_{2} \mathrm{Na}_{2} \mathrm{O}_{7} \mathrm{~S}_{2}\right.$, Sigma-Aldrich), anhydrous alcohol (Fisher Scientific Co. Ltd.), anhydrous methanol (Fisher Scientific Co. Ltd.), and Distilled water are also used through the current experiments. Deionized water (DIW) used was supplied by EASYPure RODI (U.S.A).

\section{EXPERIMENTAL PROCEDURE}

\subsection{Implementation}

Experiments for Azo dye can be done without further purification. The Experimental Producer's steps are as follows:

Optimum conditions for removing dyes were determined by dissolving $1 \mathrm{~g}$ of dye in a $1000 \mathrm{~mL}$ volumetric flask with deionized water for their aqueous solutions of initial dye concentration. Then the flask was wrapped in aluminum foil, and stored in the dark. All trials were conducted at room temperature $\left(25 \pm 2^{\circ} \mathrm{C}\right)$. A color measurement was performed using a UV / Visible spectrophotometer, using the colorimetric method. Celery leaves were washed with Tap water, then distilled water and dried at $50^{\circ} \mathrm{C}$ in an oven. The leaves were then cut into small pieces and sewn with a $2 \mathrm{~mm}$ sieve. In a flask, $200 \mathrm{~g}$ of dried leaves were added to a $1000 \mathrm{~mL}$ of distilled water, and the solution was boiled at $60^{\circ} \mathrm{C}$ for $10 \mathrm{~min}$, then filtered, and stored at $4^{\circ} \mathrm{C}$. About $10 \mathrm{~g}$ Dissolving FeSO4.7 $\mathrm{H}_{2} \mathrm{O}$ in $1 \mathrm{~L}$ distilled water. Celery extract $(250 \mathrm{ml})$ was taken and added [drop by drop] to $500 \mathrm{~mL}$ salt mixture, followed by stirring for $10 \mathrm{~min}$. The indication of the formation of C-nZVFe, the color of the solution was changed (yellow to brown than black), then the nanoparticles were collected using centrifugation for $5 \mathrm{~min}$, washed with distilled water and ethanol, the steps of preparation of C-nZVFe as shown in Schematics 1. Fenton's Reagent is prepared by dissolving $70 \mathrm{gm}$ of ferrous analytical grade sulfate $\left(\mathrm{FeSO}_{4} .7 \mathrm{H}_{2} \mathrm{O}\right)$ and $33 \%$ hydrogen peroxide in $500 \mathrm{~mL}$ of sterilized DI containing $5 \mathrm{~mL}$ of concentrated $\mathrm{H}_{2} \mathrm{SO}_{4}$ to the adjusted $\mathrm{pH}$ Fenton system.

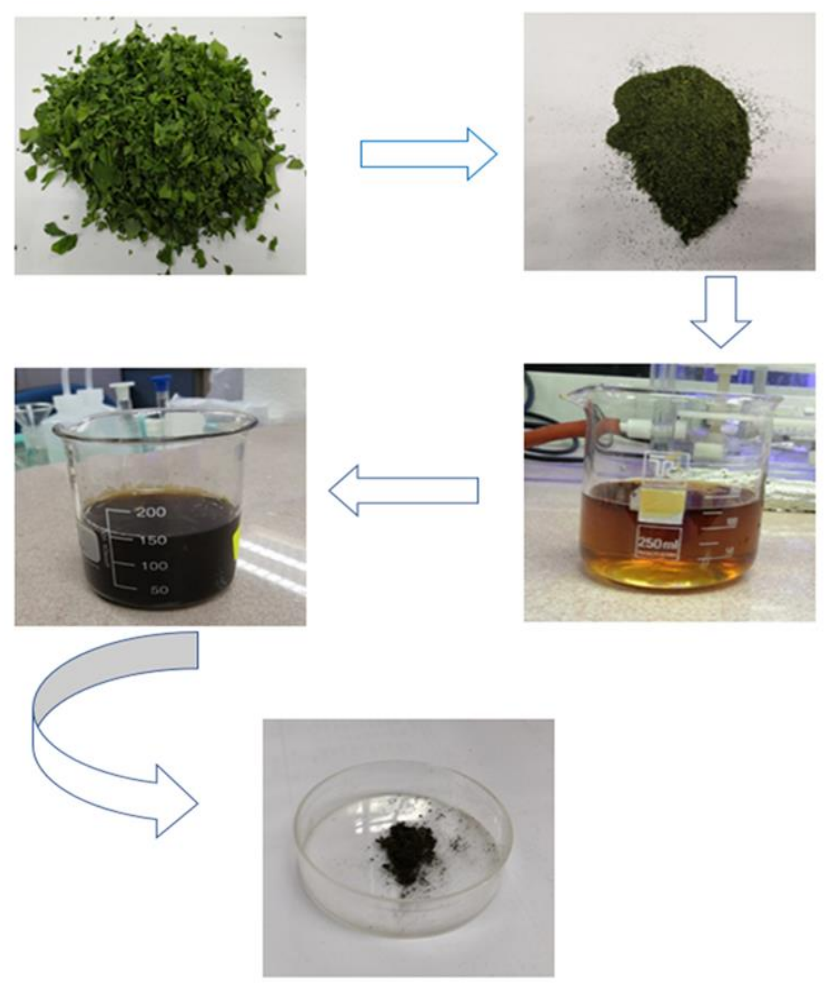

Schematics 1. The steps of preparation of C-nZVFe

\subsection{Analytical methods of OG dye}

Using a UV visual spectrophotometer (Unicam HeliosM) with a spectrometric quartz cell $(1 \mathrm{~cm}$ path length), the dye spectra was measured from 200 to 500, the standard calibration curve $(\lambda \max =478 \mathrm{~nm})$ was prepared for orange $G$ dye and the shift in dye concentration was calculated using a UV-Vis spectrophotometer. The dye color removal experiments were carried out for a volume of $100 \mathrm{~mL}$ and the dye solution was collected at every reaction time of 10, 20, 40, 60 and $80 \mathrm{~min}$. Fenton's performance on decolorization of the dye with nano iron particles was calculated using the equation below: 
Decolorization efficiency $(\%)=\frac{(C o-C t)}{C o} \times 100 \%$

where,

The Co: representing the initial concentration of $\mathrm{OG}$

$\mathrm{Ct}$ : representing the concentration of $\mathrm{OG}$ at reaction time $\mathrm{t}$ (min).

\subsection{Characterization of C-nZVFe}

To know the size of particles, components and the type of functional groups in the sample, several test and analysis were done, including Field emission Scanning electron microscope (FESEM), EDX, and FTIR spectroscopy. FESEM used to get information about the size of the particles while EDX employed to clarify the sample composition. As well, FTIR spectroscopy used to identify the chemical composition of nanoparticles prepared with C-nZVFe.

\section{RESULTS AND DISCUSSION}

\subsection{Characterization of the C-nZVFe heterogeneous Fenton catalyst}

Particles morphology of samples is investigated using Oxford-Instruments INCA 400 Nano lap field emission scanning electron microscope (FESEM). Figure 1 shows the C-nZVFe FESEM image was semi-sphere particle form and the size of these particles ranged from $40.2-55 \mathrm{~nm}$. The FESEM image shows large nano-clusters formed because of the magnetic forces between the nanoparticles C-nZVFe, and also may be due to the centrifugation process for the sample. There are many pores which enable better transportation of the orange $G$ and the spread of contamination mass to the nanoparticles inside C-nZVFe. The FESEM images show clearly that large particles are in fact agglomerates of much smaller particles; in addition, incorporation of C-nZVFe nanoparticles into pores caused forming the tiny guest particles due to the steric hindrance inside the pores shown in Figure 1.

Using FESEM / EDX the surface morphology and elemental composition have been determined. Biosynthesized C-nZVFe obtained the elemental constituents and relative abundance from Energy Dispersive X-ray (EDX), as shown in Figure 2. The EDX spectrum shows the purity of the C-nZVFe and the full chemical composition. The EDX analysis showed percentage relative composition of elements such as $\mathrm{Fe}$ (17.0\%) Oxygen (O) 28\%, Silicon (Si) 1.9\%, Carbon (C) $45.6 \%$, Potassium (K) $0.8 \%$. The highest peak due to zerovalent iron absorption signal the presence of iron nanoparticles and another peak identical to carbon and oxygen atoms reveals the vital function of organic molecules celery leaves extract in C-nZVFe constancy. FTIR measurements were conducted to understand the contribution of molecules from celery leaves extracts to the formation of nanoparticles. As shown in Figure 3, C-nZVFe's FTIR spectrum in the range 400-4000 $\mathrm{cm}^{-1}$ before the reaction. Notice that the vibration of O-H expansion lies $3779-3415 \mathrm{~cm}^{-1}$ within the wideband. Where it can be inferred from the presence of polyphenols which enhance material stability and this result is consistent with this (Soliemanzadeh \& Fekri 2017). $2926 \mathrm{~cm}^{-1}$ (C $-\mathrm{H}$ and $\mathrm{CH}_{2}$ aliphatic hydrocarbon vibration), band 1493 refer to methylene $\mathrm{CH}$, while the peak $1354 \mathrm{~cm}^{-1}$ suggests the presence of aromatic ring polyphenols $\mathrm{C}=\mathrm{C}$ stretching vibration. The shows strong peaks about $1640 \mathrm{~cm}^{-1}$ and $3300 \mathrm{~cm}^{-1}$ respectively corresponding to the alkene $(\mathrm{C}=\mathrm{C})$ stretching vibrations and phenolic hydroxyl groups $(-\mathrm{OH})$ suggesting the hydrogen bonding between the celery polyphenols. According to Figure 3, iron's presence decreases with the rise in the production and strength of phenolic compounds, which is a good indicator of C-nZVFe synthesis. This result was observed after testing more than one sample and the comparison showed that an increase in phenolic compounds results in an increase in the synthesis of nanoparticles which indicates a decrease in the presence of the iron. Although stretch vibrations of polyphenols occur in C-nZVFe, celery polyphenols do the surface behavior of nanoparticles. The results are consistent with those findings [21].

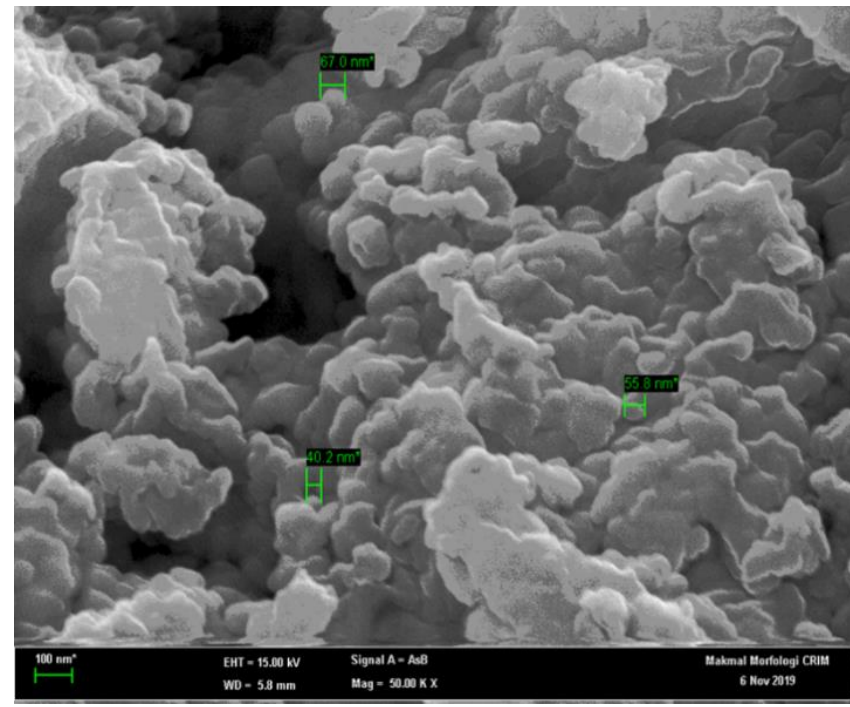

Figure 1. FESEM of prepared C-nZVFe sample

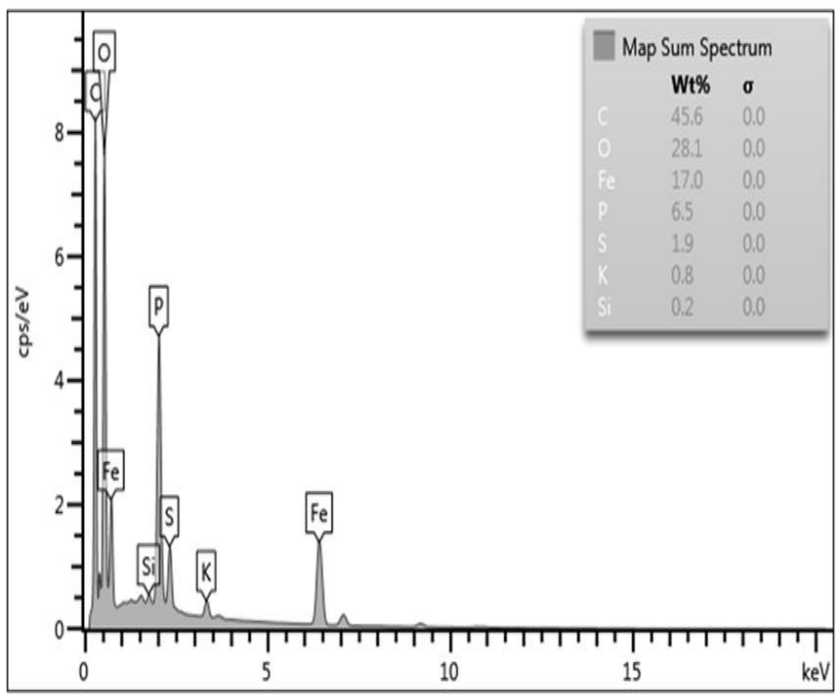

Figure 2. EDX of prepared C-n ZVFe sample 


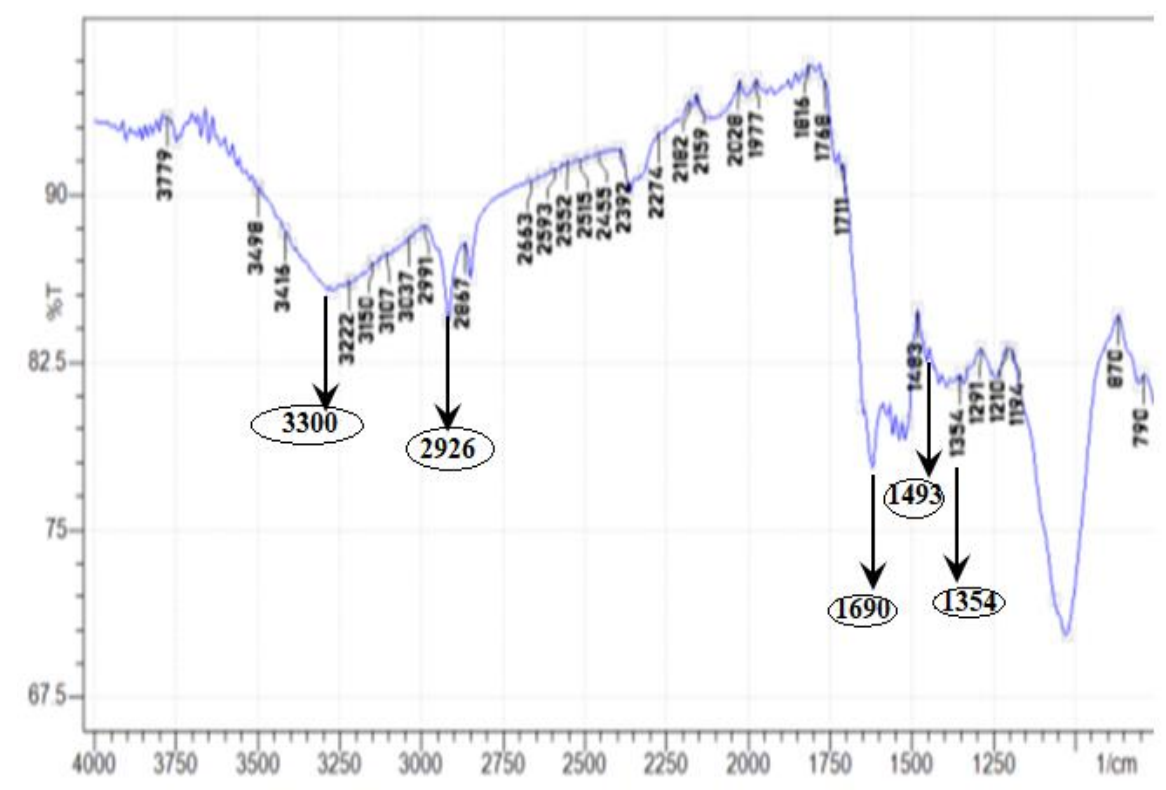

Figure 3. FTIR spectra of C-nZVFe nanoparticles celery leaves extract

\subsection{Decolorization of azo dye OG}

Figure 4 shows the process of decolorizing OG using green artificial C-nZVFe as a catalyst in the Fenton procedure, where the UV - vis spectrum of OG decolorization estimated is presented with the $\mathrm{C}-\mathrm{nZVFe} / \mathrm{H}_{2} \mathrm{O}_{2}$ reagent various reaction time. The absorption spectra of $\mathrm{OG}$ are tested in the range of $250-500 \mathrm{~nm}$. The light absorption spectrum of the OG solution consists of three major peaks at 342,396 , and $478 \mathrm{~nm}$, before reaction. The peak at $478 \mathrm{~nm}$ was due to the absorption of the naphthalene ring transition $\pi \rightarrow \pi^{*}$ in the group $-\mathrm{N}=\mathrm{N}-$, while the naphthalene ring transition in the OG molecule was within to additional bands at 342 and $396 \mathrm{~nm}$ respectively.

As shown in Figure 4, the characteristic absorption peak rapidly decreased by 396 and $478 \mathrm{~nm}$, with the reaction continuing mainly after 20 minutes. This indicates complete destruction of the chromophore systems and $\pi^{*}$. On the other hand, the area gradually dropped to about $342 \mathrm{~nm}$, suggesting that aromatic rings still exist.

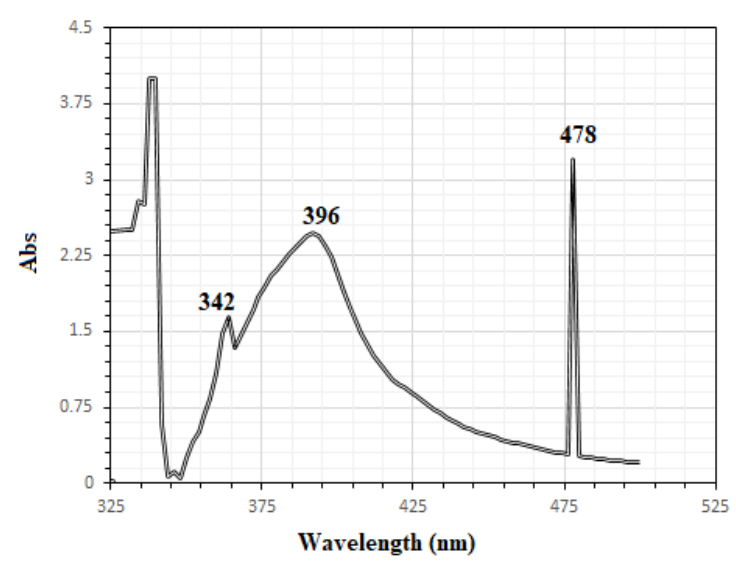

Figure 4. Analytical OG dye by UV-vis spectrophotometer

Evidently, the $\mathrm{OH}$ radicals formed in the heterogeneous Fenton method will strike azo groups and break down the $\mathrm{N}=\mathrm{N}-$ bonds, followed by the destruction of the long conjugated $\pi^{*}$ structures. Nevertheless, rapid absorption within the range of $342 \mathrm{~nm}$, at $478 \mathrm{~nm}$, which meant that certain aromatic ring intermediates existed after decoloration of the OG by the heterogeneous Fenton process.

\subsection{Effect of pH}

The effect of the $\mathrm{pH}$ value on the quantity of OG extracted by $\mathrm{C}-\mathrm{nZVFe}$ from the aqueous solution in heterogeneous Fenton was determined by conducting experiments with various $\mathrm{pH}$ values $(2.5,4,6,8$, and 10$)$ at different contact time $(10,20,4060,80 \mathrm{~min})$, and $\mathrm{pH}$ plots against the percentage of OG that was removed from the aqueous solution were shown in Figure 5.

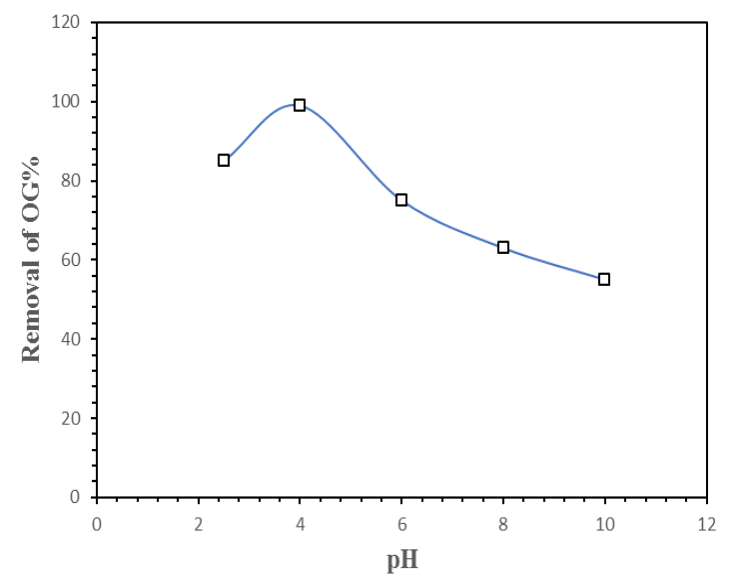

Figure 5. pH Vs. removal OG dye

The outcomes show that the catalyst's surface charge was affected by solution $\mathrm{pH}$, which convinced the deterioration of hydrogen peroxide to create hydroxy radicals and impacted contaminant removal. About $99 \%$ of OG was degraded in 20 min at $\mathrm{pH}$ of dye $(\mathrm{pH}=4)$, while the degradation efficiency was $85 \%, 75 \%, 63 \%$ and $55 \%$ after $20 \mathrm{~min}$ at $\mathrm{pH}, 2.5,6,8$ and 10 , respectively. As well, the results uncover that the color removal efficiency increases with growing $\mathrm{pH}$ and this growth are related to the adsorption ability of the catalyst at high $\mathrm{pH}$ values. Based on the results, the percentage of dye removal at 
a $\mathrm{pH}$ higher than 4 was low, due to the electrostatic repulsion between the C-nZVFe surface and the OG dye. As well, the dye molecules in the aqueous solution are slowly decomposed by the presence of the hydroxyl radical as a result of the rapid decomposition of hydrogen peroxide.

This can be seen in $\mathrm{pH}$ values below 4 , where the results tended to decrease the rate of removal of the dye a little. Furthermore, it was found that hydroxyl radicals can be formed at neutral acidity values in the C-nZVFe Fenton, which is the main cause of the dissolution of dye molecules [22]. Therefore, the reaction between the dye and the catalyst in the Fenton reaction can take place without adjusting the $\mathrm{pH}$ of the solution during the catalytic reaction.

\subsection{Effect of contact time}

The contact time is a significant operational factor influencing the efficiency of removal. Experiments are done for 10 to 80 minutes as shown Figure 11 using $35 \mathrm{mg} / \mathrm{L}$ of C$\mathrm{nZVFe}$ at $\mathrm{pH} 4$, OG initial concentration was $(100 \mathrm{mg} \backslash \mathrm{L})$ to determine the optimum time for heterogeneous Fenton efficiency in dye removal. The maximum efficiency for the decolourization was achieved at 10 and 20 min was $90 \%$ and $99 \%$.

It is clear from the Figure 6 that the improvement in removal efficiency was higher, then decrease to $85 \%, 74 \%, 66 \%$ at 40 , $60,80 \mathrm{~min}$ respectively. The explanation for the rise in the first moments is due to the rapid release of hydroxyl ions in the heterogeneous Fenton process as these ions are formed at high concentrations in the first min of the Fenton reaction. By the results of this test, it was found that the initial mineralization rate was rapid at the beginning of the reaction and continued at a slower rate after 60 and 80 minutes.

This is due to the difficulty in oxidizing all intermediate compounds present in the OG dye, such as carboxylic acids. It is worth noting that previous studies have mentioned that the hydroxyl radicals have a short lifespan, .i.e. less than nano second, and interact in the first minutes of their formation and this reveals the reason for the dye degradation in general with a short oxidation time where most of the color was removed in minute 10 and 20 , respectively.

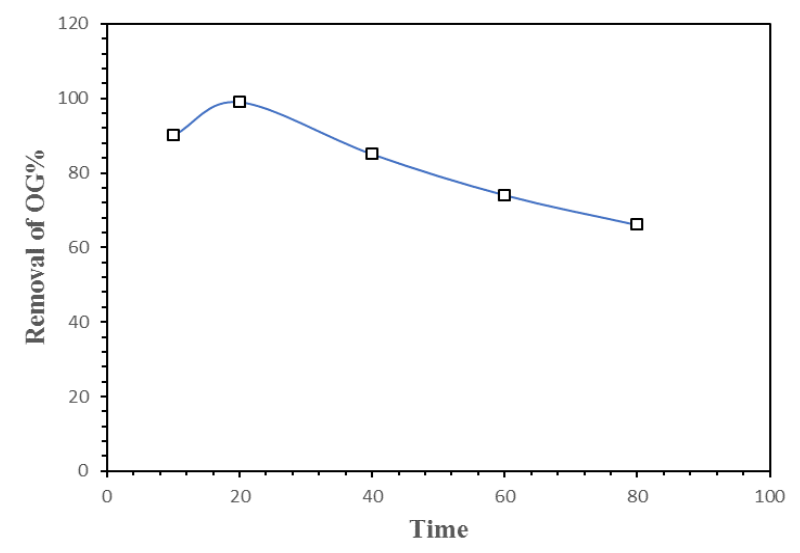

Figure 6. Contact time Vs. removal OG dye

\subsection{The effect of C-nZVFe catalyst}

The low cost of materials used in treatment processes are among the most important factors which determine the success of chemical oxidation processes in general and Fenton oxidation in particular. It is known that when the $\mathrm{Fe}^{2+}$ dose is high, the dye removal rate increases, but the continuous increase leads to the formation of sludge, which in turn makes the reaction slow and then stops.

In several experiments the effect of C-nZVFe doses of celery leaves on removal of dye was tested using different doses ranging from 5 to $50 \mathrm{mg} / \mathrm{L}$. Figure 7 shows that the efficiency of color removal reached $35 \%, 40 \%, 66 \%, 86 \%$ and $76 \%$ at different C-nZVFe 5, 10, 20, 35 and $50 \mathrm{mg} / \mathrm{L}$, respectively, at $20 \mathrm{~min}$. Accordingly, the results indicated that the color removal increased significantly with increasing $\mathrm{C}$ $\mathrm{nZVFe}$ concentration from 5 to $35 \mathrm{mg} / \mathrm{L}$.

As well, it can be seen that the slight decrease has been occurred when increasing the initial dose of C-nZVFe from 35 to $50 \mathrm{mg} / \mathrm{L}$. In the present study, a dose of C-nZVFe at 35 $\mathrm{mg} / \mathrm{L}$ can be considered the optimum for the heterogeneous Fenton system that treated aqueous solution prepared in the laboratory. This discrepancy in the percentage of removing the color from OG dye using different doses of the catalyst is due to many reasons at the forefront of which is that the concentration of $\mathrm{Fe}+2$ enhances the formation of hydroxyl radicals, which in turn facilitates decomposition of the organic materials present in the dye. In this sense, the previous researchers pointed out that the excessive amount of iron ions in the heterogeneous Fenton solution encourages the unnecessary consumption of hydroxyl ions, which has a negative effect on the OG dye's oxidative decomposition.

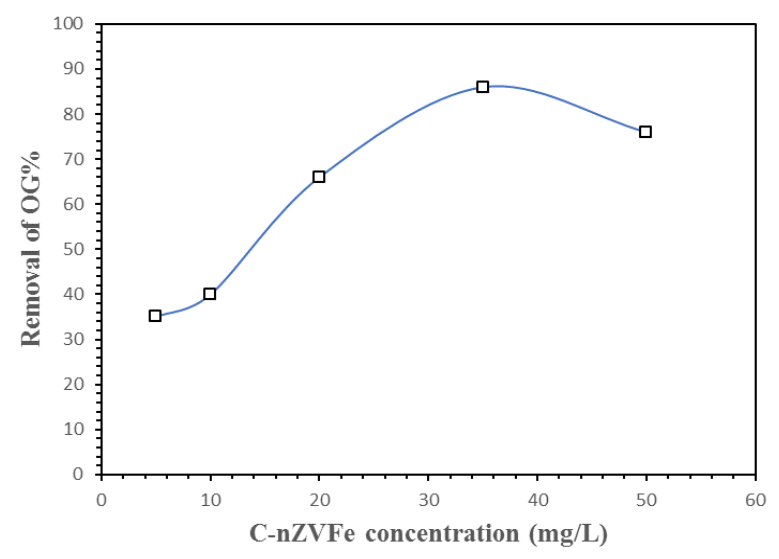

Figure 7. C-nZVFe concentration

\section{CONCLUSIONS}

In this study, Orange $\mathrm{G}$ can remove from the aqueous solutions by means of C-nZVFe. Several functional parameters have been investigated and optimized on the removal competency of Orange G. Removal affected by research conditions such as $\mathrm{pH}$, dose, contact time, the concentration of the C-nZVFe catalyst.

- From the results of the experiments for treating water by C-nZVFeFenton's oxidation, the optimum removal of Orange $\mathrm{G}$ occurred at $\mathrm{pH} 4$.

- Using different C-nZVFe concentrations (5, 10, 25, 35 and $50 \mathrm{mg} \backslash \mathrm{L}$ ) with $100 \mathrm{mg} \backslash \mathrm{L}$ of OG solution, Orange $\mathrm{G}$ removal efficiency was achieved $86 \%$. When the zerovalent nano-scale Iron dose increased from 5 to 35 $m g L^{-1}$, the removal of Orange $\mathrm{G}$ increased from $35 \%$ to $86 \%$ (initial $\mathrm{OG}=100 \mathrm{mg} \mathrm{L}^{-1}, 60 \mathrm{~min}$ ).

- The maximum efficiency for the decolourization was achieved at 10 and 20 min was $90 \%$ and $99 \%$.

- $\quad \mathrm{C}-\mathrm{nZVF}$ e is an alternative procedure which is low cost 
and environmentally friendly and the efficiency of the Fenton process can be increased by overcoming the limited $\mathrm{pH}$ range and reducing the percentage of iron sludge from the treatment process. C-nZVFe has proved to be a catalyst that can be recycled and used more than once for wastewater treatment and waste generation.

\section{ACKNOWLEDGMENT}

The authors would like to express their appreciation to Universiti Kebangsaan Malaysia for providing the test facilities for this study. Also, thanks to Makmal Morfologi CRIM from National University of Malaysia for their support as well.

\section{REFERENCES}

[1] Pang, Y.L., Abdullah, A.Z. (2013). Current status of textile industry wastewater management and research progress in Malaysia: A review. Clean-Soil, Air, Water, 41(8): 751-764. https://doi.org/10.1002/clen.201000318

[2] Gupta, V.K., Suhas. (2009). Application of low-cost adsorbents for dye removal-a review. Journal of Environmental Management, 90(8): 2313-2342. https://doi.org/10.1016/j.jenvman.2008.11.017

[3] Sohrabi, M.R., Khavaran, A., Shariati, S., Shariati, S. (2017). Removal of Carmoisine edible dye by Fenton and photo Fenton processes using Taguchi orthogonal array design. Arabian Journal of Chemistry, 10(2): S3523S3531. https://doi.org/10.1016/j.arabjc.2014.02.019

[4] Sun, S.P., Li, C.J., Sun, J.H., Shi, S.H., Fan, M.H., Zhou, Q. (2009). Decolorization of an azo dye Orange $G$ in aqueous solution by Fenton oxidation process: Effect of system parameters and kinetic study. Journal of Hazardous Materials, 161(2-3): 1052-1057. https://doi.org/10.1016/j.jhazmat.2008.04.080

[5] Wu, H.H., Dou, X.W., Deng, D.Y., Guan, Y.F., Zhang, L.G., He, G.P. (2012). Decolourization of the azo dye Orange $G$ in aqueous solution via a heterogeneous Fenton-like reaction catalysed by goethite. Environmental Technology, 33(13-15): 1545-1552. https://doi.org/10.1080/09593330.2011.635709

[6] Deng, Y., Zhao, R. (2015). Advanced oxidation processes (AOPs) in wastewater treatment. Current Pollution Reports, 1(3): 167-176. https://doi.org/10.1007/s40726-015-0015-z

[7] Oturan, M.A., Aaron, J.J. (2014). Advanced oxidation processes in water/wastewater treatment: principles and applications. A review. Critical Reviews in Environmental Science and Technology, 44(23): 25772641. https://doi.org/10.1080/10643389.2013.829765

[8] You, S.J., Teng, J.Y. (2009). Anaerobic decolorization bacteria for the treatment of azo dye in a sequential anaerobic and aerobic membrane bioreactor. Journal of the Taiwan Institute of Chemical Engineers, 40(5): 500504. https://doi.org/10.1016/j.jtice.2009.01.007

[9] Selvakumar, A., Tuccillo, M.E., Muthukrishnan, S., Ray, A.B. (2009). Use of Fenton's reagent as a disinfectant. Remediation Journal: The Journal of Environmental Cleanup Costs, Technologies \& Techniques, 19(2): 135142. https://doi.org/10.1002/rem.20208

[10] Bokare, A.D., Choi, W.Y. (2014). Review of iron-free Fenton-like systems for activating $\mathrm{H}_{2} \mathrm{O}_{2}$ in advanced oxidation processes. Journal of Hazardous Materials, 275 : 121-135. https://doi.org/10.1016/j.jhazmat.2014.04.054

[11] Macarena, M., de Pedro, Z.M., Casas, J.A., Rodriguez, J.J. (2015). Preparation of magnetite-based catalysts and their application in heterogeneous Fenton oxidation-a review. Applied Catalysis B: Environmental, 176-177: 249-265. https://doi.org/10.1016/j.apcatb.2015.04.003

[12] Sun, L., Li, Y., Li, A.M. (2015). Treatment of actual chemical wastewater by a heterogeneous Fenton process using natural pyrite. International Journal of Environmental Research and Public Health, 12(11): 13762-13778. https://dx.doi.org/10.3390\%2Fijerph121113762

[13] Liu, Y., Zhang, G., Chong, S., Zhang, N., Chang, H., Huang, T., Fang, S. (2017). NiFe $\left(\mathrm{C}_{2} \mathrm{O}_{4}\right)_{\mathrm{x}}$ as a heterogeneous Fenton catalyst for removal of methyl orange. Journal of Environmental Management, 192: 150-155. https://doi.org/10.1016/j.jenvman.2017.01.064

[14] Ezzatahmadi, N., Ayoko, G.A., Millar, G.J., Speight, R., Yan, C., Li, J., Li, S., Zhu, J., Xi, Y. (2017). Claysupported nanoscale zero-valent iron composite materials for the remediation of contaminated aqueous solutions: A review. Chemical Engineering Journal, 312: 336-350. https://doi.org/10.1016/j.cej.2016.11.154

[15] Joo, S.H., Feitz, A.J., Sedlak, D.L., Waite, T.D. (2005). Quantification of the oxidizing capacity of nanoparticulate zero-valent iron. Environmental Science \& Technology, 39(5): 1263-1268. https://doi.org/10.1021/es048983d

[16] Mu, Y., Jia, F., Ai, Z., Zhang, L. (2017). Iron oxide shell mediated environmental remediation properties of nano zero-valent iron. Environmental Science: Nano, 4(1): 2745. https://doi.org/10.1039/C6EN00398B

[17] Chang, D., Chen, T., Liu, H., Xi, Y., Qing, C., Xie, Q., Frost, R.L. (2014). A new approach to prepare ZVI and its application in removal of $\mathrm{Cr}$ (VI) from aqueous solution. Chemical Engineering Journal, 244: 264-272. https://doi.org/10.1016/j.cej.2014.01.095

[18] Danish, M., Ahmad, T. (2018). A review on utilization of wood biomass as a sustainable precursor for activated carbon production and application. Renewable and Sustainable Energy Reviews, 87: 1-21. https://doi.org/10.1016/j.rser.2018.02.003

[19] Devatha, C.P., Thalla, A.K., Katte, S.Y. (2016). Green synthesis of iron nanoparticles using different leaf extracts for treatment of domestic waste water. Journal of Cleaner Production, 139: 1425-1435. https://doi.org/10.1016/j.jclepro.2016.09.019

[20] Ali, A., Hira Zafar, M.Z., ul Haq, I., Phull, A.R., Ali, J.S., Hussain, A. (2016). Synthesis, characterization, applications, and challenges of iron oxide nanoparticles. Nanotechnology, Science and Applications, 9: 49-67. https://doi.org/10.2147/nsa.s99986

[21] Eslami, S., Ebrahimzadeh, M.A., Biparva, P. (2018). Green synthesis of safe zero valent iron nanoparticles by Myrtus communis leaf extract as an effective agent for reducing excessive iron in iron-overloaded mice, a thalassemia model. RSC Advances, 8(46): 26144-26155. https://doi.org/10.1039/C8RA04451A

[22] Blanco, M., Martinez, A., Marcaide, A., Aranzabe, E., Aranzabe, A. (2014). Heterogeneous Fenton catalyst for the efficient removal of azo dyes in water. American Journal of Analytical Chemistry, 5(8): 490. http://dx.doi.org/10.4236/ajac.2014.58058 